\title{
Auditory evoked potentials and multiple sclerosis
}

\author{
Carla Gentile Matas', Sandro Luiz de Andrade Matas², \\ Caroline Rondina Salzano de Oliveira ${ }^{3}$, Isabela Crivellaro Gonçalves ${ }^{4}$
}

\begin{abstract}
Multiple sclerosis (MS) is an inflammatory, demyelinating disease that can affect several areas of the central nervous system. Damage along the auditory pathway can alter its integrity significantly. Therefore, it is important to investigate the auditory pathway, from the brainstem to the cortex, in individuals with MS. Objective: The aim of this study was to characterize auditory evoked potentials in adults with MS of the remittent-recurrent type. Method: The study comprised 25 individuals with MS, between 25 and 55 years, and 25 age- and gender-matched healthy controls (research and control groups). Subjects underwent audiological and electrophysiological evaluations. Results: Statistically significant differences were observed between the groups regarding the results of the auditory brainstem response and the latency of the Na and P300 waves. Conclusion: Individuals with MS present abnormalities in auditory evoked potentials indicating dysfunction of different regions of the central auditory nervous system.
\end{abstract}

Key words: auditory evoked potentials, auditory brain stem evoked potentials, P300 eventrelated potentials, multiple sclerosis.

\section{Potenciais evocados auditivos e esclerose múltipla}

\section{RESUMO}

A esclerose múltipla é uma doença inflamatória desmielinizante que pode se desenvolver em diversas regiões do sistema nervoso central. O comprometimento da via auditiva central pode alterar significativamente a integridade desta e, portanto, a investigação desta região em indivíduos com esclerose múltipla, desde o tronco encefálico até o córtex, torna-se importante. Objetivo: Caracterizar os resultados dos potenciais evocados auditivos em adultos com esclerose múltipla do tipo remitenterecorrente. Método: Foram submetidos às avaliações audiológica e eletrofisiológica 25 indivíduos pertencentes ao grupo controle e 25 ao grupo pesquisa, com idades entre 25 e 55 anos. Resultados: Verificou-se diferença estatisticamente significante entre os grupos quanto à ocorrência de resultados normais e alterados no potencial evocado auditivo de tronco encefálico e latências das ondas Na e P300. Conclusão: Indivíduos com esclerose múltipla apresentam alterações nos potenciais evocados auditivos, indicando comprometimento de diferentes regiões do sistema nervoso auditivo central. Palavras-chave: potenciais evocados auditivos, potenciais evocados auditivos do tronco encefálico, potencial evocado P300, esclerose múltipla.

Multiple sclerosis (MS) is a progressive, inflammatory, demyelinating disease that was first identified by Jean Charcot in 1860. MS is caused by the destruction of the myelin sheath by autoantibodies and the di- rect action of immune cells via the infiltration of lymphocytes and monocytes. The main functions of myelin are to ensheath and electrically isolate the axons allowing nerve impulses to be conducted at high 
speeds within the brain parenchyma. Therefore, changes in brain functions observed in individuals with MS are a result of impairment in the transmission of information caused by the destruction of the myelin nerve wrap ${ }^{1}$.

MS can affect any region of the central nervous system. Therefore, special attention must be given to the central auditory nervous system because hearing function is dependent on nervous system's integrity. Thus, audiological diagnoses based only on conventional audiological evaluation do not consider the many changes that occur along the central auditory pathway, some of which are not clinically manifested ${ }^{2}$.

Auditory evoked potentials (AEP) reflect the neuroelectric activity within the auditory pathway, from the auditory nerve to the cerebral cortex, in response to an acoustic stimulus or event. The most studied AEP are the brainstem auditory evoked potential (BAEP), the auditory middle latency response (AMLR) and the cognitive potential (P300).

BAEP, which consists of seven waves generated by one or more structures along the auditory pathway, assesses the integrity of the auditory pathway from the auditory nerve to the brainstem. AMLR, consisting of a series of waves that appear after the BAEP, reflects the activation of several subcortical structures. P300 is an endogenous, event-related potential and its generation involves skills such as attention, auditory discrimination, memory and semantic perspective. It may be more correlated to the degree of global auditory dysfunction than any specific diagnosis because its results are affected by a variety of disorders that alter cognition ${ }^{3}$.

The appearance of sclerotic plaques along the auditory pathway significantly alters its integrity. Therefore, it is important to investigate the functioning of the central auditory nervous system in individuals with MS. Several studies have been performed to investigate the AEP in subjects with MS. The results of these studies varied but have mainly indicated BAEP abnormalities in MS patients ${ }^{4-7}$. Furthermore, researchers have emphasized the use of P300 as a clinical differential in patients with MS as P300 is effective in detecting cognitive dysfunctions thus increasing the chances of neuropsychological intervention with an emphasis on cognitive rehabilitation ${ }^{8-11}$.

$\mathrm{AEP}$, besides its usefulness in identifying lesions in the auditory pathway, is useful in monitoring changes in the auditory pathway. Schochat et al. ${ }^{7}$ state that although MRI has advanced the diagnosis of MS, it is feasible to use the AEP resources with precision in the follow-up treatment of pre-established profiles and in the diagnosis of new lesions that might develop, including those lesions that are clinically silent.

Due to the considerations presented, this study aimed to characterize AEP of short (BAEP) and middle (AMLR) latencies and P300 in adults with MS of the remittentrecurrent type and normal hearing. These results were compared to the results obtained in individuals with normal hearing and no history of neurological alteration.

\section{METHOD}

Institutional review board approval for this study was obtained from CAPPesq - HC/FMUSP and was registered under protocol number 274/06.

The inclusion criteria for the control group (CG) were history of normal neurological development, normal hearing thresholds, absence of psychiatric diagnoses, no complaints of tinnitus, and no auditory processing disorders. For the research group (RG), the inclusion criteria were medical diagnosis of MS of the remittent-recurrent type based on the criteria proposed by Poser et al. ${ }^{9}$, normal hearing thresholds, and no outbreak for at least six months before the recording of auditory evoked potentials. All the participants signed an inform consent.

The two groups were composed of 25 individuals each with 19 females and six males aged between 25 and 55 years (mean age of 35.16 years for the CG and of 34.88 years for the RG). Participants in the RG were referred by a neurologist. At the time of data collection the RG participants were undergoing medical follow-ups. Participants in the CG were age- and gender-matched to RG participants.

Initially, an anamnesis was performed with each participant to obtain personal data related to the history of the disease (MS), use of medications and hearing development. Information gathered during the anamnesis was confirmed by neurologists. All participants of the RG underwent MRI and received interferon beta 1a drug treatment. Of the 25 subjects evaluated, besides the characteristic lesions of MS in the central semi-oval center, two had sclerotic plaques in the regions that generate the brainstem auditory evoked potentials. It was determined from the subjects' medical histories that the average duration of disease was four years and three months. Patients were evaluated for $\mathrm{MS}^{12}$ outbreaks up until the time of data collection and the results are as follows: two had one outbreak (8\%), five had two outbreaks (20\%), four had three outbreaks (16\%), eight had four outbreaks (32\%), four had five outbreaks (16\%), one had six outbreaks (4\%) and one had seven outbreaks (4\%). According to the EDSS scale, eight patients (32\%) were in the range zero, six $(24 \%)$ in range one, eight in range two (32\%) and three (12\%) in range three.

An audiological evaluation was performed in both groups to select the individuals with normal hearing. The evaluation consisted of external ear canal inspection with the Heine ${ }^{\circ}$ otoscope, pure tone audiometry (250 to 8000 $\mathrm{Hz}$ ) and speech audiometry (speech reception threshold and speech recognition index) performed with a GSI-61 audiometer, as well as acoustic imittance measures (tym- 
panometry and acoustic reflex research, at frequencies of 500, 1000, 2000 and $4000 \mathrm{~Hz}$ ) performed with the middle ear analyzer GSI-33.

Electrophysiological evaluation consisted of recording BAEP, AMLR and P300. These evaluations were conducted on Masbe equipment - Contronic ${ }^{\circ}$ and the ATCplus $2.1^{\circ}$ software installed on a computer.

Initially, the skin of each individual was cleansed with abrasive paste and the electrodes were attached with electrolytic paste and adhesive tape and positioned according to the International Electrode System (IES) $10-20^{13}$. The value of the electrode impedance was checked prior to use and maintained below $5 \mathrm{kOhms}$. The acoustic stimulus was presented through a pair of TDH- $39^{\circ}$ headphones.

The selection of parameters for the acoustic stimulus that was used in these experiments to record the auditory evoked potentials was based on the most frequently utilized parameters in the specialized literature.

For BAEP, the acoustic stimulus used was the click, rarefaction polarity, presented monaurally at $80 \mathrm{dBnHL}$, at a rate of 19.9 clicks per second (total of 2000 stimuli) with low-pass filter of $3000 \mathrm{~Hz}$ and high-pass filter of 100 $\mathrm{Hz}$. Two recordings were obtained at the same intensity to ensure the trace reproducibility. The latencies of waves I, III, V and interpeaks I-III, III-V, I-V were marked using the standard values proposed by $\mathrm{Hall}^{3}$.

The click stimulus was used to obtain the AMLR. The stimulus was presented monaurally at $70 \mathrm{dBnHL}$, at a rate of 9.9 clicks per second (total of 1000 stimuli) with a lowpass filter of $150 \mathrm{~Hz}$ and a high-pass filter of $10 \mathrm{~Hz}$. The values of $\mathrm{Na}-\mathrm{Pa}$ amplitude at the derivations $\mathrm{C} 3 / \mathrm{A} 1, \mathrm{C} 4 /$ $\mathrm{A} 2, \mathrm{C} 3 / \mathrm{A} 2$ and C4/A1 were analyzed. The Na-Pa amplitude values were analyzed using a two-by-two design comparing the ipsilateral and contralateral values ${ }^{14}$. The $\mathrm{Pa}$ and $\mathrm{Na}$ wave latency values were also analyzed. The values proposed by McGee et al. ${ }^{15}$ were used as normality criteria.

The acoustic stimulus tone burst was used to obtain the P300. The $75 \mathrm{dBnHL}$ stimuli were randomly presented by the computer at the frequencies of $1000 \mathrm{~Hz}$ (frequent stimulus) and $1500 \mathrm{~Hz}$ (rare stimulus) at a rate of 1.1 stimuli per second with low-pass filters of $30 \mathrm{~Hz}$ and high-pass filters of $1 \mathrm{~Hz}$. The rare stimulus consisted of $15 \%$ to $20 \%$ of the total of the 300 stimuli. The individual was instructed to identify the rare stimulus by raising his/her hand every time it was heard. ${ }^{16}$ The presence and absence of this potential and the latency value of the P300 wave were marked according to the normal values proposed by McPherson ${ }^{17}$.

Results that were not in accordance with the criteria previously described were considered abnormal. The individual was considered abnormal when at least one of the ears and/or sides presented abnormality. The abnor- malities were classified according to each auditory evoked potential as follows:

For BAEP, the abnormalities were divided according to their location as follows: lower brainstem (LB) - increased latencies of waves III and V and interpeaks I-III e I-V; higher brainstem (HB) - increased latencies of wave $\mathrm{V}$ and interpeaks I-V e III-V with normal values of latencies of waves I and III; and both - LB and HB types occurring concurrently in the same individual.

For AMLR, with respect to the Na-Pa amplitude, abnormalities were classified as electrode effect, ear effect or both (the latter used when the individual presented both types of abnormalities, electrode effect and ear effect, occurring concurrently). The electrode effect is characterized by the presence of a difference greater than $50 \%$ when comparing the magnitude of measures obtained on $\mathrm{C} 3 / \mathrm{A} 1$ and $\mathrm{C} 4 / \mathrm{A} 1$ with the measures obtained on C3/ $\mathrm{A} 2$ and C4/A2. The electrode effect is, therefore, an abnormality that can be detected in the AMLR and is not linked to poor contact of the electrode. The ear effect is characterized by the presence of a difference greater than $50 \%$ when comparing the magnitude of the measures obtained on C3/A1 and C3/A2 with the measures obtained on $\mathrm{C} 4 / \mathrm{A} 1$ and $\mathrm{C} 4 / \mathrm{A} 2$. The $\mathrm{Pa}$ and $\mathrm{Na}$ wave latency values were considered abnormal when the values exceeded the adopted normal value. This abnormality was classified as latency delay.

The abnormalities observed on P300 were classified as latency delay, absence or both (the latter was used when the individual presented both types of abnormalities, latency delay and absence, occurring concurrently with one type of abnormality in each ear). Analyses of quantitative and qualitative data were performed. In the quantitative data analysis, the mean, median and standard deviation for each parameter analyzed were calculated and the between groups comparison of means was conducted. The standard tests, Anderson-Darling and the Confidence Interval for the Mean, were used for the statistical analysis of quantitative data. Regarding the qualitative data, the results were classified into normal and abnormal and further classified into types of abnormalities. The Fisher Exact Test and the Confidence Interval for Proportion were used for the statistical analysis of the qualitative data with a significance level of 0.05 (5\%). The confidence intervals of the study were calculated with a $95 \%$ statistical confidence.

\section{RESULTS}

The analyses of qualitative and quantitative data obtained from the electrophysiological hearing evaluation of the two groups are presented in this section. The BAEP values obtained from the right and left ears were pooled once no statistically significant differences for the vari- 
ables studied were observed in the comparison between ears in either group.

Statistically significant differences were observed between the control and research groups for latencies of waves III and V and interpeaks I-III and I-V, with higher values for the $R G$ (Table 1). In the analysis of the qualitative data, the RG presented significantly higher occurrence of abnormal results than the CG (Table 2). Higher occurrence of abnormalities of LB type (41\%), HB type and both abnormality types (29.5\%) was observed.

Regarding the AMLR quantitative data analysis, no statistically significant differences between groups were observed for either latency of wave $\mathrm{Pa}$ or $\mathrm{Na}-\mathrm{Pa}$ amplitude. However, there were statistically significant differences for the $\mathrm{Na}$ wave latency in the derivations $\mathrm{C} 3 / \mathrm{A} 1$, C4/A1 and C4/A2 (Table 3). The qualitative analysis of the $\mathrm{Na}$ - Pa amplitude (Table 4) demonstrated a greater percentage of abnormal results in the RG with no statistically significant difference between groups. The abnormalities most frequently observed in the CG were both (43\%) and, in the RG, the most frequently observed abnormalities were ear effect (36\%) and electrode effect (36\%). The RG also showed a higher occurrence of abnormalities in latencies of $\mathrm{Na}$ and $\mathrm{Pa}$ waves and latency delay was the most frequently observed abnormality.

For the P300 quantitative analysis, CG presented a mean latency of $313.27 \mathrm{~ms}$ and the RG presented a mean latency of $312.24 \mathrm{~ms}$ with no statistically significant difference between groups for this parameter ( $\mathrm{p}$-value $=0.853$ ).

There was no statistically significant difference between groups when comparing the occurrence of normal and abnormal results (Table 5), however, it was observed a higher percentage of abnormal results for the
RG. The type of abnormality most frequently found was the latency delay of the P300 wave (75\%).

\section{DISCUSSION}

Auditory evoked potentials are important because they provide information regarding the functional and

Table 1. Between groups comparison of BAEP mean values of absolute latencies of waves I, III and V and interpeaks I-III, III-V and I-V.

\begin{tabular}{llccc}
\hline BAEP & & Mean & SD & p-value \\
\hline Wave I & CG & 1.53 & 0.07 & 0.754 \\
Wave III & RG & 1.53 & 0.13 & \\
& CG & 3.57 & 0.09 & $0.003^{*}$ \\
Wave V & RG & 3.72 & 0.31 & \\
& CG & 5.50 & 0.45 & $0.005^{*}$ \\
Interpeak I-III & RG & 5.78 & 0.37 & \\
Interpeak III-V & CG & 2.04 & 0.06 & $0.005^{*}$ \\
& RG & 2.21 & 0.26 & \\
Interpeak I-V & CG & 1.98 & 0.08 & 0.264 \\
& RG & 2.03 & 0.27 & \\
& CG & 4.03 & 0.06 & $0.005^{*}$ \\
\hline
\end{tabular}

BAEP: brainstem auditory evoked potential; CG: control group; RG: research group; SD: standard deviation; ${ }^{*}$-value statistically significant.

Table 2. Distribution of the occurrence of normal and abnormal BAEP results in control and research groups.

\begin{tabular}{llcccccc}
\hline & & \multicolumn{2}{c}{ CG } & & \multicolumn{2}{c}{ RG } & \\
\cline { 3 - 4 } AEP & & $\mathrm{N}$ & $\%$ & & $\mathrm{~N}$ & $\%$ & p-value \\
\hline \multirow{2}{*}{ BAEP } & Normal & 25 & 100 & & 8 & 32 & $<0.01$ \\
& Abnormal & 0 & 0 & & 17 & 68 & $<0$ \\
\hline
\end{tabular}

BAEP: brainstem auditory evoked potential; AEP: auditory evoked potential; CG: control group; RG: research group.

Table 3. Between groups comparison of AMLR mean latency values of waves $\mathrm{Na}$ and $\mathrm{Pa}$ (in $\mathrm{ms}$ ) and $\mathrm{Na}$-Pa amplitude (in microvolts) in the derivations C3/A1, C3/A2, C4/A1, C4/A2.

\begin{tabular}{|c|c|c|c|c|c|c|c|c|}
\hline \multirow[b]{2}{*}{ AMLR } & \multicolumn{2}{|c|}{$\mathrm{C} 3 / \mathrm{A} 1$} & \multicolumn{2}{|c|}{$\mathrm{C} 3 / \mathrm{A} 2$} & \multicolumn{2}{|c|}{ C4/A1 } & \multicolumn{2}{|c|}{$\mathrm{C} 4 / \mathrm{A} 2$} \\
\hline & CG & RG & CG & RG & CG & RG & CG & RG \\
\hline \multicolumn{9}{|l|}{ Na Latency } \\
\hline Mean & 18.13 & 21.84 & 18.53 & 21.92 & 18.09 & 22.35 & 17.52 & 22.57 \\
\hline Median & 17.43 & 20.86 & 17.19 & 21.36 & 17.76 & 21.02 & 16.99 & 17.72 \\
\hline SD & 2.6 & 4.2 & 2.4 & 5.2 & 2.77 & 4.8 & 2.05 & 5.3 \\
\hline $\mathrm{p}$-value & \multicolumn{2}{|c|}{$0.036^{*}$} & \multicolumn{2}{|c|}{0.72} & \multicolumn{2}{|c|}{$0.045^{*}$} & \multicolumn{2}{|c|}{$0.025^{*}$} \\
\hline \multicolumn{9}{|l|}{ Pa Latency } \\
\hline Mean & 31.95 & 28.53 & 30.90 & 28.42 & 31.09 & 27.56 & 30.31 & 28.58 \\
\hline Median & 31.90 & 29.43 & 30.34 & 29.34 & 32.02 & 27.79 & 30.71 & 24.03 \\
\hline SD & 2.34 & 4.5 & 3.31 & 4.8 & 4.04 & 4.3 & 3.21 & 4.7 \\
\hline$p$-value & \multicolumn{2}{|c|}{0.84} & \multicolumn{2}{|c|}{0.66} & \multicolumn{2}{|c|}{0.75} & \multicolumn{2}{|c|}{0.44} \\
\hline \multicolumn{9}{|c|}{ Na-Pa Amplitude } \\
\hline Mean & 2.57 & 1.99 & 4.23 & 3.33 & 3.43 & 1.96 & 2.00 & 1.51 \\
\hline Median & 1.61 & 1.45 & 1.48 & 1.62 & 1.76 & 1.84 & 1.63 & 1.45 \\
\hline$p$-value & \multicolumn{2}{|c|}{0.561} & \multicolumn{2}{|c|}{0.759} & \multicolumn{2}{|c|}{0.451} & \multicolumn{2}{|c|}{0.331} \\
\hline
\end{tabular}

AMLR: auditory middle latency response; CG: control group; RG: research group; SD: standard deviation; ${ }^{*}$-value statistically significant. 
Table 4. Distribution of the occurrence of normal and abnormal AMLR results in control and research groups.

\begin{tabular}{|c|c|c|c|c|c|c|}
\hline \multirow{2}{*}{ AMLR } & & \multicolumn{2}{|c|}{ CG } & \multicolumn{2}{|c|}{ RG } & \multirow[b]{2}{*}{ p-value } \\
\hline & & $\mathrm{N}$ & $\%$ & $\mathrm{~N}$ & $\%$ & \\
\hline \multirow[t]{2}{*}{ Na Latency } & Normal & 21 & 84 & 2 & 8 & \multirow{2}{*}{$<0.01^{*}$} \\
\hline & Abnormal & 4 & 16 & 23 & 92 & \\
\hline \multirow[t]{2}{*}{ Pa Latency } & Normal & 20 & 80 & 23 & 8 & \multirow{2}{*}{0.42} \\
\hline & Abnormal & 5 & 20 & 2 & 92 & \\
\hline \multirow[t]{2}{*}{ Na-Pa Amplitude } & Normal & 18 & 72 & 11 & 44 & \multirow{2}{*}{0.08} \\
\hline & Abnormal & 7 & 28 & 14 & 56 & \\
\hline
\end{tabular}

AMLR: auditory middle latency response; CG: control group; RG: research group; ${ }^{*}$-value statistically significant.

Table 5. Distribution of the occurrence of normal and abnormal P300 results in control and research groups.

\begin{tabular}{|c|c|c|c|c|c|c|}
\hline \multirow[b]{2}{*}{ AEP } & & \multicolumn{2}{|c|}{ CG } & \multicolumn{2}{|c|}{ RG } & \multirow[b]{2}{*}{$p$-value } \\
\hline & & $\mathrm{N}$ & $\%$ & $\mathrm{~N}$ & $\%$ & \\
\hline \multirow{2}{*}{ P300 } & Normal & 25 & 100 & 21 & 84 & \multirow{2}{*}{0.11} \\
\hline & Abnormal & 0 & 0 & 4 & 16 & \\
\hline
\end{tabular}

AEP: auditory evoked potential; CG: control group; RG: research group.

structural integrity of the neural components of the auditory pathway. In the present study, electrophysiological assessment of hearing was performed through auditory evoked potential measurements in individuals with MS. The AEP can provide an objective measurement on the integrity of the auditory system as a whole ${ }^{18}$, thus reaffirming the importance of such measures in neuroscience.

Authors report that the use of evoked responses can provide a sensitive index of MS when compared to CT or even MRI ${ }^{19,20}$. Abnormalities in AEP can be identified in patients with normal MRI, especially in the case of the brain stem. Moreover, it is important to consider that such diagnostic methods assess different features of the CNS (functional versus structural; sensory pathways versus $\mathrm{CNS}$ as a whole), therefore, they are complementary. The relatively high cost of MRI, when compared to $\mathrm{AEP}$, is an additional issue to consider regarding the clinical application of these two neurodiagnostic approaches in MS patients.

Research indicates that improvement of MS symptoms has been related to changes in sensory evoked respons$\mathrm{es}^{9-11}$. This suggests that such procedures may be used to evaluate the effectiveness of treatment strategy, perhaps with more sensitivity and objectivity than neurological examination ${ }^{21}$. Additionally, MRI only evaluates the morphological data regarding the evolution of the disease in relation to the temporal and spatial aspects but does not offer information about the impact of therapy in MS.

The BAEP allows the identification of possible brainstem abnormalities. These measures are important in aiding neurological diagnosis once they have well-established criteria and a generator set. In the analysis of results obtained on the BAEP, we observed that the individuals with MS showed significantly.

longer latency values and significantly higher occurrence of abnormal results (68\%) when compared to the CG. Similar results were obtained by Celebisoy et al. ${ }^{4}$, who observed BAEP abnormalities in $60 \%$ of assessed individuals with MS. These analyses suggest the presence of abnormalities on the lower brainstem auditory pathway of individuals with MS. This is consistent with the study by Bergamaschi et al. ${ }^{5}$ who described the presence of abnormalities on the distal portion of the auditory nerve in patients with MS using MRI. Such results corroborate the findings of $\mathrm{Hall}^{3}$ regarding the electrophysiological abnormalities that may be observed in BAEP in cases of MS. These abnormalities may include increased latencies of waves III and V, increased I-III, III-V and I-V interpeaks, the absence of one or more components, and poor reproducibility and morphology of the later components suggesting dyssynchrony.

BAEP abnormalities were also reported by Santos et al. ${ }^{6}$. The authors observed BAEP abnormality in 58.62\% of the individuals with MS with no signs of brainstem involvement according to the MRI. The types of abnormalities observed were poor wave morphology, increased I-V interpeak, the presence of only wave I, or the absence of the latest waves with normal first absolute latencies. Lima et al. ${ }^{22}$ also reported BAEP abnormalities in 36\% of individuals with MS.

Therefore, data found in this and in other studies ${ }^{4-7}$ reinforce the importance of recording the BAEP in cases of clinical suspicion of demyelinating diseases and especially with proven diagnosis of MS, because BAEP recording aids in the diagnosis and the definition of the type of brain impairment presented. Moreover, the record can provide information about the functional aspect of improvement after treatment. As BAEP is an objective, easy and inexpensive method, it can be performed serially to evaluate the effectiveness of treatment. This is difficult to accomplish with MRI given its high cost. 
The AMLR is considered one of the best tests to evaluate the central auditory nervous system, and it is also a useful tool in the design and monitoring of the therapeutic process. There are few studies in the literature that use the AMLR as an electrophysiological measure for the investigation of the auditory pathway in patients with MS. In the present study, RG presented higher incidence of abnormal results than the CG with respect to the $\mathrm{Na}$ - $\mathrm{Pa}$ amplitude and the latencies of $\mathrm{Pa}$ and $\mathrm{Na}$ waves. However, this difference was not statistically significant. The abnormalities of higher occurrence in the RG were ear effect, electrode effect, and delay in latencies of $\mathrm{Pa}$ and $\mathrm{Na}$ waves. The presence of AMLR abnormalities in individuals with MS was also evidenced by Celebisoy et al. ${ }^{4}$ who reported the occurrence of abnormalities in $73.4 \%$ of individuals assessed. AMLR abnormalities were also observed in the MS case study presented by Schochat et al. ${ }^{7}$, thus demonstrating the possibility of involvement of the auditory pathway at the subcortical level.

The latency of the P300 wave is the most reliable index for analysis of this potential ${ }^{17}$. Statistically significant differences between groups were not observed in either the qualitative or quantitative analysis. However, regarding the distribution of normal and abnormal results, it was observed that the RG showed higher percentage of abnormal results than the CG. The latency delay was the type of abnormality most frequently observed.

The findings of this study regarding the presence of P300 abnormalities in individuals with MS and the types of abnormalities often encountered, corroborate those described by Schochat et al. ${ }^{7}$, Magnano et al. ${ }^{8}$, Giesser et al. ${ }^{23}$, Gonzáles-Rosa et al. ${ }^{24}$, Newton et al.$^{25}$, Gil et al. ${ }^{26}$, and Dijk et al. ${ }^{27}$.

Several studies ${ }^{8-11,18,23,24,28}$ describe the presence of cognitive changes in patients with MS demonstrating that they may present dysfunctions in memory, attention, verbal fluency, task performance, and visual perception, all of which are important skills related to P300. These data justify the use of this potential, in association with other tests, in evaluation and follow-up of MS as reported by Magnano et al. ${ }^{8}$, Aminoff and Goodin ${ }^{9}$, Magnié et al. ${ }^{10}$ and Kurokawa et al. ${ }^{29}$. In MS, the CNS electrophysiological evaluations performed through visual evoked potentials, auditory evoked potentials of short latency, and somatosensory potentials are well-established.

Although the visual and somatosensory evoked potentials have greater sensitivity than the AEP, the use of a multimodal battery promotes increased sensitivity when compared to using a single modality alone. Thom$\mathrm{as}^{30}$ states that when used in combination with structural and functional MRIs, the electrophysiological measures can provide additional information regarding the temporal dynamics of brain activity. Moreover, accord- ing to Aminoff and Goodin ${ }^{9}$ and Stockard and Rossiter ${ }^{21}$, there is a relationship between improvement of symptoms and reversal of abnormalities in somatosensory potential, suggesting that this potential could be used in assessing the effectiveness of medical treatment. Furthermore, the AMLR and event-related potentials have been widely studied because of their correlation with cognitive aspects. The abnormalities observed in these potentials are defined by the increase of the latency waves or by the absence of characteristic peaks ${ }^{6}$.

Thus, considering that individuals with MS may present abnormalities in AEP and this procedure is both inexpensive and easy to implement, we would like to emphasize that AEP can be considered by neurologists as an additional useful tool in assessing and monitoring of individuals with MS.

In conclusion, individuals with MS of the remittentrecurrent type present abnormalities in BAEP. This suggests that the brainstem auditory pathway, in the regions from the cochlear nucleus to the lateral lemniscus, may be disrupted due to structural and/or functional changes in the transmission of the acoustic stimulus along the auditory pathway. Abnormalities in AMLR suggest impairment in subcortical regions of the auditory pathway and/or central auditory processing disorder. The presence of abnormalities in cognitive potential (P300) suggests impairment in cortical regions of the auditory pathway and deficits in cognitive processing, memory, attention and auditory discrimination. Taking into consideration these aspects and the fact these individuals have hearing thresholds within normal limits, the combination of different objective methods of electrophysiological assessment of hearing (BAEP, AMLR and P300) contributes to the detection of changes in central auditory pathway in individuals with MS.

\section{REFERENCES}

1. Ropper AH, Brown RH. Multiple sclerosis and allied demyelinative diseases. In: Ropper AH, Brown RH (Eds). Adams and Victors Principles of neurology. $8^{\text {th }}$ Ed. New York: McGraw-Hill, 2005:771-796.

2. Mustillo P. Auditory deficits in multiple sclerosis: a review. Audiology 1984; 23:145-164.

3. Hall III JW. Handbook of auditory evoked responses. Boston: Allyn and Bacon, 2007

4. Celebisoy N, Aydogdu I, Ekmekci O, Akurekli O. Middle latency auditory evoked potentials (MLAEPS) in MS. Acta Neurol Scand 1996;93:318-321.

5. Bergamaschi R, Romani A, Zappoli F, Versino M, Cosi V. MRI and brainstem auditory evoked potential evidence of eighth cranial nerve involvement in multiple sclerosis. Neurology 1997;48:270-272.

6. Santos MAR, Lana-Peixoto MA, Munhoz MSL, Almeida AV. Avaliação dos potenciais evocados auditivos do tronco encefálico na esclerose múltipla. Arq Neuropsiquiatr 2003;61:392-397.

7. Schochat E, Matas CG, Sanches SGG, Carvallo RMM, Matas S. Central auditory evaluation in multiple sclerosis Arq Neuropsiquiatr 2006;64:872-876.

8. Magnano I, Aiello I, Piras, MR. Cognitive impairment and neurophysiological correlates in MS. J Neurol Sci 2006;245:117-122.

9. Aminoff JC, Goodin DS. Long-latency cerebral event-related potentials in multiple sclerosis. J Clin Neurophysiol 2001;18:372-377. 
10. Magnié MN, Bensa C, Laloux L, Bertogliati C, Faure S, Lebrun C. Contribution of cognitive evoked potentials for detecting early cognitive disorders in multiple sclerosis. Rev Neurol 2007;163:1065-1074.

11. Fletcher S, Vardi J, Finkelstein Y, Pollak L. Cognitive dysfunction evaluation in multiple sclerosis patients treated with interferon beta 1-b: an open-label prospective 1 year study. Isr Med Assoc J 2007;9:457-459.

12. Poser $C M$, Paty DW, Scheinberg $L$, et al. New diagnostic criteria for multiple sclerosis: guidelines for research protocols. Ann Neurol 1983;13:227-231.

13. Jasper HA. The ten-twenty system of the International Federation. Electroencephalogr Clin Neurophysiol 1958,10:371-375

14. Musiek FE, Lee WW. Potenciais auditivos de média e longa latência. In: Musiek FE, Rintelmann WF (Eds). Perspectivas atuais em avaliação auditiva. Barueri: Manole, 2001:239-256.

15. McGee T, Kraus N, Manfredi C. Toward a strategy for analyzing the auditory middle-latency response waveform. Audiology 1988;27:119-130.

16. Picton TW. The P300 wave of the human event-related potential. J Clin Neurophysiol 1992;9:456-479.

17. McPherson DL. Late potentials of the auditory system. San Diego: Singular Pub. Group, 1996.

18. Rao SM, Leo GJ, Bernardin L, Unverzagt F. Cognitive dysfunction in multiple sclerosis. I. Frequency, patterns, and prediction. Neurology 1991;41:685-691.

19. Giesser BS, Kurtzberg D, Vaughan Jr HG, et al. Trimodal evoked potentials compared with magnetic resonance imaging in the diagnosis of multiple sclerosis. Arch Neurol 1987:44:281-284.

20. Tramo MJ, Schneck MJ, Lee BCP, Rapoport S. Evoked potentials and mag- netic resonance imaging in the diagnosis of multiple sclerosis. Neurology 1985:35(Suppl 1):S105.

21. Stockard JJ, Rossiter VS. Clinical and pathologic correlates of brainstem auditory response abnormalities. Neurology 1977;27:316-325.

22. Lima TMA, Crato AN, Mancini PC, Simões LC, Gonçalves DU. Alterações dos potenciais evocados auditivos do tronco encefálico em pacientes com esclerose múltipla. Braz J Otorhinolaryngol 2009;75:177-181.

23. Giesser BS, Schroeder MM, LaRocca NG, Kurtzberg D Ritter W, Vaughan HG, Scheinberg LC. Endogenous event-related potentials in multiple sclerosis patients. Eletroenceph Clin Neurophisiol 1992;82:320-329.

24. Gonzales-Rosa JJ, Vazquez-Marrufo M, Vaquero E, et al. Diferential cognitive impairment for diverse forms of multiple sclerosis. BMC Neurosci 2006;7:39.

25. Newton MR, Barret G, Callanan MM, Towell AD. Cognitive event-related potentials in multiple sclerosis. Brain 1989;112:1637-1660.

26. Gil R, Zai L, Neau JP, Jonveaux T, et al. Event-related auditory evoked potentials and multiple sclerosis. Eletroenceph Clin Neurophysiol 1993;88:182-187.

27. Dijk JG, Jennekens-Schikel A, Caekebeke JFV, Singh A, Zwinderman AH. What is the validity of an "abnormal" evoked or event-related potential in MS. J Neurol Sci 1992;109:11-17.

28. Fischer JS. Cognitive impairment in multiple sclerosis. In: Cook SD (Ed). Handbook of multiple sclerosis. New York: Marcel Dekker, 2001:233-255.

29. Kurokawa T, Kira J, Tobimatsu S. Electrophysiolgical diagnosis for multiple sclerosis. Nippon Rinsho 2003;61:1347-1354.

30. Thomas KM. Assessing brain development using neurophysiologic and behavioral measures. J Pediatr 2003;143(Suppl 4):S46-S53. 